\title{
Effect of prophylactic tranexamic acid on blood conservation in Indian women undergoing abdominal hysterectomy
}

\author{
Nivedhana Arthi P. ${ }^{1}$, Jalakandan B. ${ }^{2 *}$, Gunaseelan S. ${ }^{2}$
}

\begin{abstract}
${ }^{1}$ Department of Obstetrics and Gynecology, ${ }^{2}$ Department of Anaesthesiology, Sri Venkateshwaraa Medical College Hospital and Research Centre, Pondicherry, India
\end{abstract}

Received: 29 July 2018

Accepted: 03 August 2018

\author{
*Correspondence: \\ Dr. Jalakandan B., \\ E-mail: dr_jalakandan@yahoo.co.in
}

Copyright: (c) the author(s), publisher and licensee Medip Academy. This is an open-access article distributed under the terms of the Creative Commons Attribution Non-Commercial License, which permits unrestricted non-commercial use, distribution, and reproduction in any medium, provided the original work is properly cited.

\begin{abstract}
Background: The prevalence of anemia in India is so high that majority of women presenting for hysterectomy are already with borderline hemoglobin status and the perioperative blood loss puts them at risk of death and prolongs recovery. Antifibrinolytic agents, mainly Tranexamic acid (TXA) have been demonstrated to reduce blood loss and transfusion requirements in various surgeries. The present study was done to assess the efficacy of TXA in effectively reducing intraoperative blood loss and the need for transfusion in Indian population undergoing abdominal hysterectomy for benign indications.

Methods: This randomized, double-blind, placebo-controlled study was conducted on hundred patients undergoing abdominal hysterectomy. Group T $(\mathrm{n}=50)$ - received TXA $15 \mathrm{mg} / \mathrm{kg}$ in $100 \mathrm{ml}$ Normal saline and Group N $(\mathrm{n}=50)$ received the same volume of Normal saline infused over 15 minutes. Estimated blood loss, need for blood transfusion, duration of surgery, postoperative hemoglobin and incidence of adverse events were noted.

Results: There was statistically significant reduction in mean blood loss in group $\mathrm{T}$ when compared to group $\mathrm{N}$ (360 $\mathrm{ml}$ versus $540 \mathrm{ml}$ ). Accordingly, there was significant difference in the number of patients requiring blood transfusion (12\% versus $42 \%)$ and also the postoperative hemoglobin levels. The group $\mathrm{T}$ patients had a significantly shorter operating time (127.86 versus 148.64 minutes). None of the patients developed any major adverse events.

Conclusions: The prophylactic TXA safely and effectively reduces the blood loss and transfusion requirements in Indian patients undergoing abdominal hysterectomy for benign indications.
\end{abstract}

Keywords: Abdominal hysterectomy, Anemia, Antifibrinolytics, Fibrinolysis, Perioperative bleeding, Tranexamic acid

\section{INTRODUCTION}

Anemia continues to be a significant public health problem affecting 1.62 billion of the world's population. ${ }^{1}$ According to Global nutrition report 2017, India comes at the bottom of the table with $51 \%$ women suffering from anemia. Hysterectomy is one of the frequently performed major gynecological surgical procedures for various uterine pathologies. Even when the indication for the procedure is benign, relatively high complication rates have been reported. And the most common cause of complications is perioperative bleeding. Surgery affects the coagulation systems and consequent to the increased release of plasminogen activator inhibitor, the fibrinolytic system shuts down, thus leading to coagulopathy and bleeding. ${ }^{2}$ A normal woman can tolerate a blood loss of up to $1000 \mathrm{~mL}$ with a minimal effect on their health status whereas in a woman with severe anemia or cardiovascular disease, a blood loss of as little as $200 \mathrm{~mL}$ may be life-threatening and require additional intervention. ${ }^{3}$ Given the magnitude of burden of anemia in India, majority of women presenting for hysterectomy 
are already anemic and the perioperative blood loss puts them at risk of death and increases recovery time. So perioperative blood transfusion had become more of a routine practice in these patients. Blood products are a scarce resource and are not without risks. To minimize the transfusion requirements, various blood conservation strategies has to be carried out. Antifibrinolytic agents, mainly Tranexamic acid (TXA), Epsilon amino caproic acid (EACA) and Aprotinin, have been demonstrated to reduce blood loss and transfusion requirements in various elective surgeries. $^{4}$

TXA, a synthetic analogue of lysine, inhibits fibrinolysis by competitively binding to plasminogen. It prevents the lysis of formed clot by inhibiting activation of plasminogen and plasmin. ${ }^{5}$ It has been shown to be very useful for reducing blood loss during and after surgical procedures and also the need for blood transfusion. A number of Cochrane systematic reviews conducted in a variety of surgical settings had reported the efficacy of prophylactic perioperative administration of TXA in reducing blood loss and the need for blood transfusion. ${ }^{6-10}$ TXA has already been demonstrated to reduce uterine blood loss in non-surgical aspect. Various studies had revealed that TXA resulted in a significant reduction of menstrual blood loss in menorrhagic women while not increasing the risk of thrombosis and had been used successfully to treat menorrhagia associated with a number of coagulopathies. ${ }^{11-13}$ Shaaban et al and Kongnyuy et al had reported that TXA reduced blood loss during myomectomy by a mean volume of $407 \mathrm{~mL}$ and $243 \mathrm{~mL}$ respectively. ${ }^{6,10}$ Topsoee et al in their randomized controlled trial had concluded that TXA could reduce the total blood loss, the incidence of substantial blood loss, and the need for reoperations for patients who underwent benign hysterectomy. ${ }^{9}$ More common adverse events of TXA include nausea, vomiting, diarrhoea, dyspepsia and headache. ${ }^{14}$ But no serious adverse effects have been reported and the increased risks of thrombosis have not been demonstrated in clinical trials. ${ }^{15,16}$

TXA gained worldwide recognition and acceptance in the 2010 Clinical Randomization of an Antifibrinolytic in Significant Hemorrhage (CRASH-2) trial, a multinational randomized placebo-controlled trial of TXA in adult trauma patients with significant bleeding. ${ }^{17}$ TXA significantly reduced the risk of death as a result of bleeding by about a sixth and reduced the risk of all cause mortality by about a tenth. As the result of CRASH-2 trial, the World health organization (WHO) added TXA injection for the treatment of adult patients with trauma and significant risk of ongoing hemorrhage to the Selection and Use of Essential Medicines guideline (March 2011). ${ }^{18}$ The European societies (Task Force for Advanced Bleeding Care in Trauma and the European Society of Anesthesiology) had recommended the use of TXA in the case of traumatic and perioperative bleeding, under class 1A recommendation. ${ }^{19}$ The 2015 American society of Anesthesiologists (ASA) practice guidelines for perioperative blood management recommended consideration of TXA in surgical patients with excessive bleeding. ${ }^{20}$

In this study, an attempt was made to translate this positive response of TXA in effectively reducing intraoperative blood loss and the need for transfusion in Indian population undergoing abdominal hysterectomy for benign indications.

\section{METHODS}

This randomized, double-blind, placebo-controlled study was conducted on hundred patients undergoing abdominal hysterectomy during the period of January 2017 to June 2018. After getting clearance from the ethics committee of our institution and obtaining informed consent from the patients, they were randomized into two groups using sealed envelope technique: Group $\mathrm{T}(\mathrm{n}=50)$ - Tranexamic acid group and Group N ( $n=50)$ - Normal saline (Placebo) group.

\section{Inclusion criteria}

- Women $\geq 18$ years of age

- ASA physical status $\leq 3$

- Abdominal hysterectomy for any benign indication including but not limited to dysfunctional uterine bleeding, uterine fibroids, adenomyosis, pelvic inflammatory disease, adnexal mass or endometriosis.

- Hysterectomy in combination with unilateral/bilateral salpingectomy or oophorectomy, ovarian cystectomy, appendectomy or cystoscopy

\section{Exclusion criteria}

- History of hypersensitivity to TXA

- Known or suspected endometrial/ovarian/cervical cancer

- Hysterectomy for endometrial hyperplasia or cervical dysplasia

- Patients currently undergoing treatment for any type of cancer.

- known bleeding/clotting disorders or a history of thromboembolism (including deep venous thrombosis or pulmonary embolism) or treatment with anticoagulants within the past month

- History of myocardial infarction within the last year; present unstable angina or severe coronary artery disease

- Serious respiratory disease

- Acquired defective color vision

- Preoperative hepatic or renal dysfunction

- Severe psychiatric or mental disorder.

The clinical history and the relevant investigations were noted. To achieve a minimum hemoglobin of $10 \mathrm{~g} / \mathrm{dL}$ before surgery, Packed red blood cell concentrate 
(PRBC) was transfused 48 hours preoperatively in needed patients. Hemoglobin measurements were repeated on the previous day of surgery in the hospital laboratory. Prior to the day of surgery, anesthesiologists had evaluated all the patients. The patients were advised fasting as per ASA guidelines.

All patients had standard premedications. On arrival in the theatre, twelve-lead ECG (leads II and V5) for heart rate (HR) and ST segment changes, Pulse oximetry (SpO2), and non-invasive blood pressure monitors were attached, and baseline readings were recorded. All the patients were administered General anesthesia through standard institutional protocol. An anesthesiologist, who was not involved in the study prepared the study solution. The volume of TXA (15 mg/kg body weight, $100 \mathrm{mg} / \mathrm{mL}$ ampoule) or the same volume of placebo $(0.9 \% \mathrm{NaCl})$ was added to a $100-\mathrm{mL}$ Normal saline bag. The patients then received the study solution as an intravenous infusion given over 15 minutes.

Both the surgeon and anesthesiologist were blinded to the treatment regimen. After 20 minutes, the skin incision was commenced. All the surgeries were performed by three experienced gynecologists. Perioperative bleeding was managed according to clinical practice. If patients developed signs of hemodynamic instability due to blood loss (heart rate $>120$ beats/min or a systolic blood pressure $<20 \%$ of baseline value) despite adequate volume replacement, PRBC was transfused.

The mean arterial blood pressure was maintained during surgery. The placement of drains was allowed but not encouraged. Following surgery, the patients were transferred to post-anesthesia care unit for further observation.

Postoperative hemoglobin was ascertained at 24 hours. All the patients were closely observed for signs and symptoms of thromboembolic phenomena and other adverse events. Doppler ultrasound of lower limbs was done daily for three days in all patients for signs of deep vein thrombosis.

\section{Calculation of blood loss}

Intra-operative blood loss was estimated by gravimetric method. Drapes (4), sponges (20), abdominal pads (5) were weighed beforehand. At the end of the surgery, the drapes, sponges, gauze were weighed again in an electronic weighing machine. Difference in weight was noted. One mg weight was taken as equivalent to $1 \mathrm{ml}$ of blood. Blood loss during surgery was measured as follows. Amount of blood loss $(\mathrm{ml})=($ weight of sponges, pads and drapes after surgery - weight of sponges, pads and drapes prior to surgery) + amount of blood collected in suction container.

\section{Outcome}

- Estimated blood loss

- Hemoglobin at 24 hours postoperatively

- Need for blood transfusion

- Duration of operative procedure

- Incidence of postoperative thromboembolic events (deep venous thrombosis, pulmonary embolism, myocardial infarction, stroke)

- Incidence of other adverse events (headache, seizure, visual disturbances, nausea/vomiting, diarrhoea).

\section{Statistical analysis}

Statistical analysis was performed using Statistical Package for Social Sciences (SPSS Inc., Chicago, Illinois, USA) version 23. Quantitative parameters were performed using students' t-test whereas qualitative parameters are compared using Chi square test and fisher exact test. Data are shown as mean \pm standard deviation and in absolute numbers or percentages. $\mathrm{p}<0.05$ was considered statistically significant.

\section{RESULTS}

The demographic characteristics with regard to age, height and weight were comparable and the distribution of patients among ASA physical status classification were also similar between both the groups.

Table 1: Preoperative patient characteristics.

\begin{tabular}{|llll|}
\hline Characteristics & Group T & Group N & p value \\
\hline Age (years)* & $39.88 \pm 5.28$ & $40.28 \pm 5.11$ & $0.351 \mathrm{NS}$ \\
\hline Height $(\mathrm{cms})^{*}$ & $155.62 \pm 5.11$ & $155.46 \pm 5.43$ & $0.44 \mathrm{NS}$ \\
\hline Weight $(\mathrm{Kg})^{*}$ & $57.9 \pm 11.9$ & $58.68 \pm 10.7$ & $0.366 \mathrm{NS}$ \\
\hline ASA I/2/3 (No. of patients) & $14 / 29 / 5$ & $15 / 27 / 8$ & $0.83 / 0.69 / 0.37 \mathrm{NS}$ \\
\hline Baseline Systolic blood pressure $(\mathrm{mmHg})^{*}$ & $128.94 \pm 11.38$ & $126.08 \pm 9.65$ & $0.089 \mathrm{NS}$ \\
\hline Baseline Diastolic blood pressure (mmHg)* & $81.18 \pm 8.63$ & $79.76 \pm 7.03$ & $0.185 \mathrm{NS}$ \\
\hline Preop Hemoglobin $(\mathrm{g} / \mathrm{dL})^{*}$ & $11.1 \pm 0.56$ & $11.06 \pm 0.54$ & $0.365 \mathrm{NS}$ \\
\hline Platelet count $\left(\mathrm{x} 10^{3} / \mu \mathrm{L}\right)^{*}$ & $244.4 \pm 41.41$ & $237.92 \pm 39.69$ & $0.213 \mathrm{NS}$ \\
\hline Prothrombin time $(\mathrm{sec})^{*}$ Control-12 sec & $12.3 \pm 0.54$ & $12.38 \pm 0.64$ & $0.25 \mathrm{NS}$ \\
\hline Activated partial Thromboplastin time (sec)* Control-34 sec & $34.88 \pm 1.06$ & $34.8 \pm 1.07$ & $0.354 \mathrm{NS}$ \\
\hline Preoperative blood transfusion (No. of patients)** & $14(28 \%)$ & $17(34 \%)$ & $0.517 \mathrm{NS}$ \\
\hline
\end{tabular}

*Data as Mean \pm standard deviation; **Data as number of patients (percentage); NS-Not significant 
The preoperative Systolic and Diastolic blood pressures did not differ significantly and the preoperative parameters like hemoglobin, platelet count, prothrombin time, activated partial thromboplastin time were similar in both the groups. To achieve a minimum hemoglobin of $10 \mathrm{~g} / \mathrm{dL}$ before surgery, $28 \%$ of patients in group $\mathrm{T}$ and $34 \%$ of patients in group $\mathrm{N}$ received 1 unit of PRBC 48 hours preoperatively and the difference was not statistically significant (Table 1). Similarly, the number of patients in each category of indications for hysterectomy were also comparable (Table 2). Thus, the preoperative patient characteristics in both the groups were similar and comparable.

The mean estimated blood loss in group $\mathrm{T}$ and group $\mathrm{N}$ were $360.16 \pm 107.1 \mathrm{ml}$ and $540.22 \pm 121.9 \mathrm{ml}$ respectively. Thus, there was a significant reduction in mean blood loss in group $\mathrm{T}$ when compared to group $\mathrm{N}$ and the difference was statistically very significant $(\mathrm{p}<0.00001)$. Accordingly, there was significant difference in the need for perioperative transfusion and the postoperative hemoglobin levels (Table 3).

Table 2: Indications for abdominal hysterectomy.

\begin{tabular}{|c|c|c|c|}
\hline Indications & Group T & Group N & p-value \\
\hline Fibromyoma & $17(34 \%)$ & $21(42 \%)$ & $0.41 \mathrm{NS}$ \\
\hline Adenomyosis & $4(8 \%)$ & $5(10 \%)$ & $0.73 \mathrm{NS}$ \\
\hline $\begin{array}{l}\text { Dysfunctional } \\
\text { uterine bleeding }\end{array}$ & $\begin{array}{l}16 \\
(32 \%)\end{array}$ & $\begin{array}{l}11 \\
(22 \%)\end{array}$ & $0.26 \mathrm{NS}$ \\
\hline Endometriosis & $1(2 \%)$ & $0(0 \%)$ & NS \\
\hline $\begin{array}{l}\text { Pelvic inflammatory } \\
\text { disease }\end{array}$ & $7(14 \%)$ & $10(20 \%)$ & $0.42 \mathrm{NS}$ \\
\hline Adnexal mass & $5(10 \%)$ & $3(6 \%)$ & $0.46 \mathrm{NS}$ \\
\hline
\end{tabular}

Data as number of patients (percentage); NS: Not significant

In Group T, $12 \%$ patients required one unit of PRBC transfusion compared to $42 \%$ patients in Group $\mathrm{N}$ and it was statistically significant ( $p<0.00001)$. In both the groups, none of the patients required more than one unit of PRBC transfusion intraoperatively.

Table 3: Outcomes.

\begin{tabular}{|llll|}
\hline Characteristics & Group T & Group N & p-value \\
\hline Estimated blood loss (mL)* & $360.16 \pm 107.1$ & $540.22 \pm 121.9$ & $<0.00001 \mathrm{~S}$ \\
\hline Postoperative Hemoglobin (g/dL)* & $9.78 \pm 0.44$ & $9.24 \pm 0.42$ & $<0.00001 \mathrm{~S}$ \\
\hline Perioperative Blood transfusion (No. of patients)** & $6(12 \%)$ & $21(42 \%)$ & $0.0007 \mathrm{~S}$ \\
\hline Duration of surgery (minutes)* & $127.86 \pm 14.94$ & $148.64 \pm 13.47$ & $<0.00001 \mathrm{~S}$ \\
\hline *Data as Mean+Standard Deviation; **Data as number of patients (percentage); S.Significant &
\end{tabular}

*Data as Mean \pm Standard Deviation; **Data as number of patients (percentage); S:Significant

The postoperative hemoglobin measured at 24 hours postoperatively was significantly lower in group $\mathrm{N}$ $(9.24 \pm 0.42 \mathrm{~g} / \mathrm{dL})$ when compared to group $\mathrm{T}(9.78 \pm 0.44$ $\mathrm{g} / \mathrm{dL})$. The group $\mathrm{T}$ patients had a significantly shorter operating time (127.86 versus 148.64 minutes).

Table 4: Incidence of adverse events.

\begin{tabular}{|llll|}
\hline Adverse events & Group T & Group N & p value \\
\hline Nausea & $5(10 \%)$ & $3(6 \%)$ & $0.461 \mathrm{NS}$ \\
\hline Vomiting & $1(2 \%)$ & $1(2 \%)$ & $1 \mathrm{NS}$ \\
\hline Diarrhoea & $1(2 \%)$ & $1(2 \%)$ & $1 \mathrm{NS}$ \\
\hline $\begin{array}{l}\text { Thromboembolic } \\
\text { phenomena }\end{array}$ & $0(0 \%)$ & $0(0 \%)$ & --- \\
\hline $\begin{array}{l}\text { Seizures } \\
\text { Visual }\end{array}$ & $0(0 \%)$ & $0(0 \%)$ & --- \\
disturbances & $0(0 \%)$ & $0(0 \%)$ & --- \\
\hline
\end{tabular}

Data as number of patients (percentage); NS: Not significant

There was insignificant incidence of minor adverse effects like nausea, vomiting and diarrhoea in both the groups. None of the patients in both the groups developed any major adverse events, followed up to three days postoperatively (Table 4).

\section{DISCUSSION}

Anemia is the most prevalent nutritional deficiency disorder in the world. According to the National Family Health Survey-III, more than half of women in India $(55 \%)$ have anemia, including $39 \%$ with mild anemia, $15 \%$ with moderate anemia and $2 \%$ with severe anemia. ${ }^{21}$ Over the 7-year period, anemia prevalence increased significantly from $51.3 \%$ to $56.1 \%$ among Indian women. This corresponded to a 1.11-fold increase in anemia prevalence after adjustment for age and parity. ${ }^{22}$ Hysterectomy is one of the most frequently performed major gynecological surgical procedures. Even when the surgery is performed for benign indications, relatively high complication rates have been reported because of perioperative bleeding. With such a high prevalence of anemia in India, majority women present themselves with borderline hemoglobin status and does not tolerate even small volume blood loss as occurring during surgery, necessitating perioperative blood transfusion. Blood is a scarce and costly resource and blood transfusion is not without risks. It has several rare but serious adverse effects. Worldwide, most people do not have access to safe blood. The risk of hemolytic reaction, anaphylaxis, acute lung injury and infection transmission are 
associated with blood transfusion. Transfusion can also have potential of adverse immune consequences and end organ effects.

A popular conservative approach is to minimize perioperative bleeding through the prophylactic use of antifibrinolytic agents. ${ }^{4}$ Tissue injury and injury to the arterial or venous wall, exposes the perivascular tissue factor expressing cells to blood and thereby triggers the activation of the blood clotting system. ${ }^{23}$ Initially, thrombin activates the conversion of fibrinogen into fibrin. Subsequently the fibrinolytic process is activated by the conversion of plasminogen into plasmin, an enzyme necessary in the breakdown of fibrin. This fibrinolysis is stimulated by endogenous activators like tissue plasminogen activator and urokinase plasminogen activator. Plasmin activity is also modulated by various naturally occurring plasminogen activator inhibitors to achieve equilibrium between clot formation and breakdown. ${ }^{14}$ Although fibrinolysis is a part of a normal physiological response to tissue damage, any disturbance in the balance between activators and inhibitors of the fibrinolytic system as seen during surgery, may result in hyperfibrinolysis and hence excessive bleeding. ${ }^{14}$ Antifibrinolytics works by preventing the breakdown of blood clots and thereby reduces bleeding.

Antifibrinolytic agents in current use include the naturally occurring serine protease inhibitor Aprotinin, the synthetic protease inhibitor Nafamostat and the synthetic lysine analogues EACA and TXA. ${ }^{24}$ TXA, a 4aminomethyl cyclohexane carbolic acid exerts an antifibrinolytic effect through the reversible blockade of the lysine-binding sites on the plasminogen molecule, thereby inhibiting clot degradation. It is a competitive inhibitor of plasminogen activation. Compared to other synthetic lysine analogues, TXA has a higher antifibrinolytic efficacy in peripheral tissue and a longer half-life of 3.1 hours. ${ }^{14}$ It can be administered orally, intravenously and topically. Its onset of action after intravenous administration is $5-15$ minutes and oral bioavailability ranging from $30-50 \%$. With a plasma protein binding of $3 \%$, it can completely cross the placenta. TXA is minimally metabolized and mainly excreted unchanged by the kidneys. ${ }^{5,14}$ Therefore, dosage adjustment is required in renal impairment and is unnecessary in hepatic impairment. Besides being a potent antifibrinolytic, TXA has antiinflammatory properties at higher doses because of its inhibition of plasmin and by blocking the binding of $\alpha_{2}$-antiplasmin. It is also speculated that plasmin inhibitors such as TXA have anti-cancer and anti-ageing properties. ${ }^{25}$ Absolute contraindications for TXA include hypersensitivity to the drug, pre-existing active thromboembolic disorder, disseminated intravascular coagulation, renal failure, coronary or vascular stent placed within one year, acquired defective colour vision and acute subarachnoid hemorrhage. Relative contraindications include uncontrolled seizure disorder, renal dysfunction, high risk of venous or arterial thrombosis, or pre-existing coagulopathy or anticoagulant treatment. ${ }^{26}$

There has been consistent results about the significant role of TXA in blood conservation in various settings, from trauma to cardiac, neurological, orthopedic, craniofacial, obstetric and gynaecological surgery. ${ }^{6-8,27}$ Ker et al in their systematic review of randomized clinical trials on the effect of TXA on surgical blood loss had revealed that TXA reduces the probability of blood transfusion by $38 \% .{ }^{16}$ With growing evidence about the positive effects of TXA on perioperative bleeding and transfusion rate, this randomized, double-blinded, placebo-controlled study was conducted with the objective of determining whether a single prophylactic dose of TXA given intravenously can reduce perioperative blood loss and also the need for blood transfusion in patients undergoing abdominal hysterectomy.

The preoperative patient characteristics were comparable between both the groups. The dose of TXA used was 15 $\mathrm{mg} / \mathrm{kg}$ body weight. Goswami et al had compared the efficacy of two different doses of TXA in their study and inferred that $15 \mathrm{mg} / \mathrm{kg}$ dose was more effective than 10 $\mathrm{mg} / \mathrm{kg}$ dose without increase in adverse effects. ${ }^{28}$ The same dose had been employed in many other studies. ${ }^{29,30}$ Rapid bolus administration of TXA might result in a drop in blood pressure and should be avoided. When TXA was given intraoperatively, it does not decrease bleeding significantly because the cascade of fibrinolytic activation is most easily inhibited in its earlier phase. ${ }^{2}$ Bhavana et al had demonstrated statistically significant decrease in blood loss when TXA was administered with time gap of $20-40$ minutes. ${ }^{31,32}$ Thus the drug was administered as an intravenous infusion over 15 minutes and the skin incision was commenced after 20 minutes. The duration of surgery was significantly longer in placebo treated group. The observed reduction in blood loss in TXA treated group would have contributed for shorter operating time, by providing a relatively clear operating field and avoiding unnecessary wastage of time in controlling the bleeding. Similar observation had been made in many other studies. ${ }^{10,23,33}$

The primary outcome measure was estimated blood loss. Accurate determination of blood loss is difficult. In this study, the intra-operative blood loss was estimated by gravimetric method. Other methods used for blood loss estimation are visual, direct and photometric methods. Inspite of being most inaccurate, visual method is commonly used. Photometric method is considered most accurate but it is complex and costly. Though gravimetric method gives only approximate estimation, it is considered to be the most practical. ${ }^{34}$

There was significant reduction in blood loss in patients receiving TXA $(360 \mathrm{ml}$ vs $540 \mathrm{ml})$ and was statistically very significant. This difference have greater importance in developing countries like India, where one in every 
two women are anemic. Topsoee et al in their study on effects of prophylactic TXA treatment in patients undergoing benign hysterectomy had demonstrated significant reduction in perioperative blood loss in TXA treated group. ${ }^{9}$ Similar observation was made by Shaaban et al in their study on the efficacy of TXA in reducing blood loss in patients undergoing open myomectomy. ${ }^{10}$ Lundin ES et al had observed a mean reduction of estimated blood loss of $248 \mathrm{ml}$ in patients undergoing ovarian cancer surgery. ${ }^{30}$ Hence there was increased need for blood transfusion in group $\mathrm{N}(42 \%)$ compared to TXA treated group (12\%) and it was statistically significant. Shaaban et al and Shady NW et al in their study on assessing the efficacy of TXA in patients undergoing open myomectomy had observed that placebo treated group required more transfusions when compared to TXA treated group (34.8\% versus $19.7 \%$ and $54.3 \%$ versus $17.1 \%$ respectively). ${ }^{10,33}$ Celebi et al had observed $30 \%$ reduction in the amount of perioperative bleeding and recommended the use of TXA for decreasing the need for blood transfusion in gynecological cancer surgery, in view of the negative effects of blood transfusions. ${ }^{35}$ Gupta et al also had observed significantly less intraoperative blood loss, shorter operative time and lower transfusion rate (risk reduced by $56 \%$ ) during radical surgery. ${ }^{32}$ These blood sparing effects of TXA would definitely be useful in reducing the transfusion requirements especially in the anemic subgroup, where the incidence of transfusion generally tends to be high. On cost analysis, TXA use was found to be much more cost-effective in comparison to blood transfusion. ${ }^{28}$

Despite the finding that placebo group received significantly more PRBC transfusions, the postoperative hemoglobin levels were significantly higher in TXA treated group when compared to the placebo (9.78 versus $9.24 \mathrm{~g} / \mathrm{dL}$ ). Shaaban et al had also reported significantly lower postoperative hemoglobin levels in the placebo group. ${ }^{10}$

Though minor adverse events like nausea, vomiting, diarrhoea, dyspepsia and headache were common and transient, there are still some concerns regarding the safety of TXA use in view of risks like seizures, thromboembolic phenomena and visual disturbances. ${ }^{14}$ The risk of seizures is likely multifactorial, but certainly increases with TXA exposure and with higher dosing regimes. ${ }^{36}$ It has been postulated that central nervous system inhibition mediated by binding of TXA to lysine binding sites of inhibitory glycine and GABA(Gama Amino Butyric acid typeA) receptors could be the underlying mechanism for seizures..$^{37,38}$ The incidence of postoperative seizures in cardiac surgical patients receiving high TXA doses has been reported to be as high as $7.3 \%$ compared to $1.0 \%$ in placebo group. ${ }^{39}$ In contrast, in a large cohort of around 1600 children having craniofacial surgery there was no significant difference in the incidence of seizures. ${ }^{40}$
As a result of inhibiting fibrinolysis, though there is a theoretical possibility of an increased risk of thromboembolic events, it is biologically unlikely when used in situations where there is a shift from physiological fibrinolysis to hyperfibrinolysis (as seen during major surgery and trauma). Inhibition of hyperfibrinolysis by TXA restores the balance of the hemostatic system. Numerous clinical trials have not reported any evidence for an increased risk of thromboembolic events with TXA in various clinical situations, including trauma and surgery. ${ }^{8,15,16}$ Recent evidence from the CRASH-2 trial of TXA in bleeding trauma patients showed a statistically significant reduction in mortality with no increase in thromboembolic effects and indeed, there was a statistically significant reduction in the risk of myocardial infarction. ${ }^{17}$

In this study, the incidence of minor adverse effects like nausea, vomiting and diarrhoea were low and was comparable between both the groups. There was no incidence of major adverse events like seizures, thromboembolic phenomena and visual disturbances in both the groups. Topsoee et al and Shady NW et al also had not reported any major adverse events in the TXA treated patients. ${ }^{9,33}$ Goswami et al in their study on effect of TXA on postpartum blood loss had made an observation that inspite of 5-6 times higher incidence of thrombosis during pregnancy and puerperium, no increased risk of thrombosis was found. ${ }^{28}$ Similarly, despite the fact that malignancy is a hypercoagulable state, Gupta et al and Lundin ES et al in their study on efficacy of TXA in cancer surgery had revealed no significant incidence of major adverse events..$^{30,32}$

\section{CONCLUSION}

A single prophylactic dose of TXA given immediately before surgery seems to be a cost-effective way of reducing the blood loss, transfusion rate and operating time significantly in patients undergoing abdominal hysterectomy for benign indications. With proper attention to the contraindications, Tranexamic acid may be safely recommended as standard prophylactic treatment in abdominal hysterectomy especially in developing countries like India. Further extensive studies are needed to validate our findings.

Funding: No funding sources

Conflict of interest: None declared

Ethical approval: The study was approved by the Institutional Ethics Committee

\section{REFERENCES}

1. McLean E, Cogswell M, Egli I. Worldwide prevalence of anaemia, WHO vitamin and mineral nutrition information system, 1993-2005. Public Health Nutr. 2009;12:444-54. 
2. Murphy WG, Davies MJ, Eduardo A. The haemostatic response to surgery and trauma. $\mathrm{Br} \mathrm{J}$ Anaesth. 1993;70:205-13.

3. Chi BH. Translating clinical management into an effective public health response for postpartum haemorrhage. BJOG. 2015;122:211.

4. Levy JH, Dutton RP, Hemphill JC, Shander A, Cooper D, Paidas MJ. Hemostasis Summit Participants: Multidisciplinary approach to the challenge of hemostasis. Anesth Analg. 2010;110:354-64.

5. Wellington K, Wagstaff AJ. Tranexamic acid: Review of its use in management of menorrhagia. Drugs. 2003;63:1417.

6. Kongnyuy E, Wiysonge C. Interventions to reduce haemorrhage during myomectomy for fibroids. Cochrane Database Syst Rev. 2011 Nov 9;(11):CD005355.

7. Novikova N, Hofmeyr GJ, Cluver C. Tranexamic acid for preventing postpartum haemorrhage. Cochrane Database Syst Rev. 2015 Jun 16;(6):CD007872.

8. Perel P, Ker K, Morales Uribe $\mathrm{CH}$, Roberts I. Tranexamic acid for reducing mortality in emergency and urgent surgery. Cochrane Database Syst Rev. 2013 Jan 31;1(1):CD010245.

9. Topsoee MF, Bergholt T, Ravn P, Schouenborg L, Moeller C, Ottesen B et al. Anti-hemorrhagic effect of prophylactic tranexamic acid in benign hysterectomy-a double-blinded randomized placebocontrolled trial. Am J Obstet Gynecol. 2016 Jul;215:72.e1-8.

10. Shaaban MM, Ahmed MR, Farhan RE. Efficacy of tranexamic acid on myomectomy- associated blood loss in patients with multiple myomas: a randomized controlled clinical trial. Reprod Sci. 2016;23:908-12.

11. Lethhaby A, Farquhar C, Cook I. Antifibrinolytics for heavy menstrual bleeding. Cochrane Database Syst Rev. 2000;(4):CD000249.

12. Chi C, Pollard D, Tuddenham EG. Menorrhagia in adolescents with inherited bleeding disorders. J Pediatr Adolesc Gynecol. 2010;23:215-22.

13. Mohri H. High dose of tranexamic acid for treatment of severe menorrhagia in patients with vonWillebrand disease. J Thromb Thrombolysis. 2002; 14:255-7.

14. Mc Cormack PL. Tranexamic acid: a review of its use in the treatment of hyperfibrinolysis. Drugs. 2012;72(5):585-617.

15. Dunn CJ, Goa KL. Tranexamic acid: a review of its use in surgery and other indications. Drugs. 1999;57:1005-32.

16. Ker K, Edwards P, Perel P, Shakur H, Roberts I. Effect of tranexamic acid on surgical bleeding: systematic review and cumulative meta-analysis. BMJ. 2012;344:e3054.

17. Shakur H, Roberts I, Bautista R, et al. Effects of tranexamic acid on death, vascular occlusive events, and blood transfusion in trauma patients with significant haemorrhage (CRASH-2): a randomised, placebo-controlled trial. Lancet. 2010;376:23-32.

18. World Health Organization. Summary of the report of the 18th meeting of the WHO Expert Committee on the Selection and Use of Essential Medicines. Available at http://www.who.int/selection_medicines/committees/ TRS_web_summary.pdf. Published March 2011.

19. Kozek-Langenecker SA, Afshari A, Albaladejo P, Santullano CA, De Robertis E, Filipescu DC et al. Management of severe perioperative bleeding: guidelines from the European Society of Anaesthesiology. Eur J Anaesthesiol. 2013;30:270382

20. American Society of Anesthesiologists Task Force on Perioperative Blood Management. Practice guidelines for perioperative blood management: an updated report by the American Society of Anesthesiologists Task Force on Perioperative Blood Management. Anesthesiology. 2015;122:241-75.

21. National Family Health Survey (NFHS-III), 2005$2006 . \quad$ Available http://www.nfhsindia.org/pdf/India.

22. Balarajan YS, Fawzi WW, Subramanian SV. Changing patterns of social inequalities in anaemia among women in India: cross-sectional study using nationally representative data. BMJ Open. 2013;3(3):e002233.

23. Mahdy AM, Webster NR. Perioperative systemic haemostatic agents. Br J Anaesth. 2004;93:842-58.

24. Verstraete M. Clinical application of inhibitors of fibrinolysis. Drugs. 1985;29:236-61.

25. Al-Horani RA, Desai UR. Recent advances on plasmin inhibitors for the treatment of fibrinolysisrelated disorders. Med Res Rev. 2014;34:1168-216.

26. Goobie SM. Tranexamic acid: still far to go. Br J Anaesth. 2017;118(3):293-5.

27. Ortmann E, Besser MW, Klein AA. Antifibrinolytic agents in current anaesthetic practice. Br J Anaesth. 2013;111:549-63.

28. Goswami U, Sarangi S, Gupta S, Babbar S. Comparative evaluation of two doses of tranexamic acid used prophylactically in anaemic parturients for lower segment cesarean section: A double-blind randomized case control prospective trial. Saudi J Anaesth. 2013;7(4):427-31.

29. Hiippala ST, Strid LJ, Wennerstrand MI, Arvela JV, Niemela HM, Mantyla SK, et al. tranexamic acid radically decreases blood loss and transfusions associated with total knee arthroplasty. Anesth Analg. 1997;84:839-44.

30. Lundin ES, Johansson T, Zachrisson H, Leandersson U, Backman F, Falknas L, et al. Single-dose tranexamic acid in advanced ovarian cancer surgery reduces blood loss and transfusions: double-blind placebo-controlled randomized multicenter study. Acta Obstet Gynecol Scand. 2014;93(4):335-44.

31. Bhavana G, Abhishek MV, Suneeta Mittal. Efficacy of prophylactic tranexamic acid in reducing blood 
loss during and after caesarean section. Int J Reprod Contracept Obstet Gynecol. 2016Jun;5(6):2011-6.

32. Gupta K, Rastogi B, Krishan A, Gupta A, Singh VP, Agarwal S. The prophylactic role of tranexamic acid to reduce blood loss during radical surgery: A prospective study. Anesth Essays Res. 2012;6:70-3.

33. Shady NW, Sallam HF, Fahmy H. Reducing blood loss during open myomectomy with intravenous versus topical tranexamic acid: A double-blinded randomized placebo-controlled trial. Middle East Fertil Soc J. 2018.

34. Ashraf Aly H, Ramadani HM. Assessment of blood loss during cesarean section under general anesthesia and epidural analgesia using different methods. AJAIC. 2006;9(1).

35. Celebi N, Celebioglu B, Selcuk M, Canbay O, Karagoz AH, Aypar U. The role of antifibrinolytic agents in gynecological cancer surgery. Saudi Med J. 2006;27:637-41.

36. Lecker I, Wang DS, Whissell PD, Avramescu S, Mazer CD, Orser BA. Tranexamic acid-associated seizures: causes and treatment. Ann Neurol. 2016;79:18-26.

37. Lecker I, Wang DS, Romaschin AD, Peterson M, Mazer CD, Orser BA. Tranexamic acid concentrations associated with human seizures inhibit glycine receptors. J Clin Invest. 2012;122:4654-66.

38. Kratzer S, Irl H, Mattusch C, Bürge M, Kurz J, Kochs $\mathrm{E}$ et al. Tranexamic acid impairs gammaamino butyric acid receptor type A-mediated synaptic transmission in the murine amygdala: a potential mechanism for drug-induced seizures? Anesthesiology. 2014;120:639-49.

39. Kalavrouziotis D, Voisine P, Mohammadi S, Dionne $\mathrm{S}$, Dagenais F. High-dose tranexamic acid is an independent predictor of early seizure after cardiopulmonary bypass. Ann Thorac Surg. 2012;93:148-54

40. Goobie SM, Cladis FP, G CD, Huang H, Reddy SK, Fernandez A, et al. Safety of antifibrinolytics in cranial vault reconstructive surgery: a report from the pediatric craniofacial collaborative group. Paediatr Anaesth. 2017;27(3):271-81.

Cite this article as: Arthi NP, Jalakandan B,

Gunaseelan S. Effect of prophylactic tranexamic acid on blood conservation in Indian women undergoing abdominal hysterectomy. Int J Reprod Contracept Obstet Gynecol 2018;7:3538-45. 